\title{
BMJ Open Traditional medicine used in childbirth and for childhood diarrhoea in Nigeria's Cross River State: interviews with traditional practitioners and a statewide cross-sectional study
}

\author{
Iván Sarmiento, ${ }^{1,2}$ Germán Zuluaga, ${ }^{1,2}$ Neil Andersson³
}

To cite: Sarmiento I, Zuluaga G, Andersson N. Traditional medicine used in childbirth and for childhood diarrhoea in Nigeria's Cross River State: interviews with traditional practitioners and a statewide cross-sectional study. BMJ Open 2016;6: e010417. doi:10.1136/ bmjopen-2015-010417

- Prepublication history and additional material is available. To view please visit the journal (http://dx.doi.org/ 10.1136/bmjopen-2015010417).

Received 30 October 2015 Revised 14 March 2016 Accepted 22 March 2016

\section{CrossMark}

${ }^{1}$ Centro de Estudios Médicos Interculturales (CEMI), Cota, Cundinamarca, Colombia ${ }^{2}$ Escuela de Medicina y Ciencias de la Salud, Universidad del Rosario, Bogotá, Colombia ${ }^{3}$ CIET/PRAM, Department of Family Medicine, McGill University, Montreal, Québec, Canada

Correspondence to Professor Iván Sarmiento; isarmiento@cemi.org.co

\section{ABSTRACT}

Objectives: Examine factors associated with use of traditional medicine during childbirth and in management of childhood diarrhoea.

Design: Cross-sectional cluster survey, household interviews in a stratified last stage random sample of 90 census enumeration areas; unstructured interviews with traditional doctors.

Setting: Oil-rich Cross River State in south-eastern Nigeria has 3.5 million residents, most of whom depend on a subsistence agriculture economy.

Participants: 8089 women aged 15-49 years in 7685 households reported on the health of 11305 children aged 0-36 months in July-August 2011.

Primary and secondary outcome measures:

Traditional medicine used at childbirth and for management of childhood diarrhoea; covariates included access to Western medicine and education, economic conditions, engagement with the modern state and family relations. Cluster-adjusted analysis relied on the Mantel-Haenszel procedure and Mantel extension.

Results: $24.1 \%$ (1371/5686) of women reported using traditional medicine at childbirth; these women had less education, accessed antenatal care less, experienced more family violence and were less likely to have birth certificates for their children. $11.3 \%$ (615/ 5425 ) of young children with diarrhoea were taken to traditional medical practitioners; these children were less likely to receive $B C G$, to have birth certificates, to live in households with a more educated head, or to use fuel other than charcoal for cooking. Education showed a gradient with decreasing use of traditional medicine for childbirth $\left(\chi^{2} 135.2\right)$ and for childhood diarrhoea $\left(\chi^{2} 77.2\right)$.

Conclusions: Use of traditional medicine is associated with several factors related to cultural transition and to health status, with formal education playing a prominent role. Any assessment of the effectiveness of traditional medicine should anticipate confounding by these factors, which are widely recognised to affect health in their own right.

\section{Strengths and limitations of this study}

- Locally recruited and trained interviewers conducted all interviews in the local language.

- Secondary analysis of data from a large study of health service coverage in a statewide representative sample provided interpretable data on use of traditional medicine.

- Interviews with traditional medical practitioners oriented the analysis and enriched interpretation of results.

- The original study was not focused on the use of traditional medicine, so only a few questions about this were included in the survey.

\section{INTRODUCTION}

The WHO supports integration of traditional medicine into national health systems. ${ }^{1}$ Reactions to the idea of bringing traditional medicine into the mainstream of health systems range from 'a noncritical enthusiasm to an uninformed scepticism'. ${ }^{2}$ Important obstacles to integration of traditional medicine include lack of evidence about the effectiveness of traditional medicine, and a narrowly quantitative approach is not well suited to investigate the impact of traditional medicine. ${ }^{3}$

A central concern of modern epidemiology is to explore causality and investigate confounding in associations. Poverty, lack of education and low coverage of Western medical services are recognised covariates of the use of traditional medicine, but these factors are also determinants of health status in their own right, making it difficult to untangle the impact of traditional medicine on health status. ${ }^{4}$

Nigeria has a notoriously poor coverage with Western health services, ${ }^{5}$ high rates of 
preventable morbidity and mortality, ${ }^{6}$ and a high level of unsatisfied basic health needs. ${ }^{7}$

In recent years, there has been growing scientific interest in traditional medicine in African countries and recognition of its role in meeting healthcare needs. ${ }^{8} 9$ Traditional medicine is known to be widely used in Nigeria, but there is only weak evidence on how many people use it or who they are. ${ }^{10-12}$

The Nigerian Evidence-based Health System Initiative (NEHSI ${ }^{13}$ was a collaboration between the Government of Nigeria, the International Development Research Centre and the Department of Foreign Affairs, Trade and Development of Canada. As part of this initiative in Cross River State, a series of statewide cross-sectional household surveys (2009, 2011 and 2013) complemented routine information with information on health conditions, their management and associated factors in women and children.

The present secondary analysis of data from the 2011 survey examined the use of traditional medicine in the context of available Western health services, education levels, economic status, family relations and engagement with the modern state in Nigerian communities. The study sought to determine the level of use of traditional medicine by households in Cross River State and to examine the factors associated with the use of traditional medicine, including the availability of Western health services.

\section{METHODS}

The 2011 survey covered a stratified (region, urban/ rural) last stage random sample of 90 census enumeration areas in all 18 local government areas (LGAs) in Cross River State. ${ }^{14}$ Sample size estimation at the design stage suggested that 8012 women aged 15-49 years in 90 clusters would be sufficient to detect a $20 \%$ change over 2 years in a maternal outcome (perinatal sepsis) affecting $24 \%$ of pregnancies at baseline $(80 \%$ power, $\alpha$ error $5 \%$, Intraclass Correlation Coefficient (ICC) 0.01 ), if $50 \%$ of the women were pregnant each year.

In July and August of 2011, locally recruited and trained interviewers administered a 35-item household questionnaire (see online supplementary material 1 ) to one respondent in each household and a team member completed a 44-item community profile (see online supplementary material 2) with the help of a local community leader. Local female interviewers administered an additional 108-item instrument (see online supplementary material 3) in face-to-face interviews with female household members aged $15-49$ years. Those who were pregnant during the past 2 years were asked who had assisted them in childbirth and where they delivered. The questionnaire asked the caregivers (nearly always the mothers) of children aged 0-36 months about common illnesses and the primary and secondary management of episodes of these illnesses. The overall questionnaires provided data which have been analysed and published in eight other journal articles. ${ }^{14-21}$
Field supervisors piloted the instruments in similar communities and we made small adjustments to the instruments before the main data collection.

During the fieldwork for the household survey, one of the authors (IS) interviewed traditional medical practitioners in 60 of the 90 clusters. Using an intercultural dialogue format, ${ }^{22}$ the researcher shared his experience of the subject to establish a two-way exchange of information in which the traditional medical practitioner could feel comfortable. All interviews were anonymous. The dialogue informed categories of analysis and interpretation of the results.

\section{Analysis}

Self-reported use of traditional medicine during childbirth included deliveries attended by traditional medical practitioners, traditional birth attendants or religious/ spiritual healers.

Mothers reported where they sought treatment for the most recent episode of diarrhoea in children aged 0 36 months, and responses included visiting traditional medicine practitioners of various sorts. The questions allowed reporting of the first choice and second choice for treatment ('Where, if anywhere, did you seek treatment for the child for the diarrhoea?' and 'Where else did you seek treatment?'). We defined access to Western medicine during pregnancy as self-reported attendance for antenatal care at government or private medical services. We used vaccination with BCG as evidence of availability of Western healthcare for childhood illness ('Has this child received BCG injection given at birth into the left arm?'). ${ }^{23}$

We examined potential associations between selfreported use of traditional medicine and access to Western medicine, and four other sets of social and economic variables: education, economic status, family relations and engagement with the modern state. We defined five levels for education of the woman/mother, of the household head, and of the father of the child: no education, elementary school, junior high school, senior high school, and higher education. Elements of economic conditions/status included: housing construction (better construction was cement in walls and zinc roof); self-reported household financial situation (above or below community average); source of drinking water (safer supply was from a tap, borehole or tube well); cooking fuel used (higher economic status was using fuel other than charcoal or wood), whether the household had enough food during the past week; household location (whether living in hard-to-reach communities); and whether the community was urban or rural. Family relations included self-reported exposure to physical or verbal abuse, and communication with the partner about pregnancy and delivery. Engagement with the modern state included whether the community had electricity, and whether the child had a birth certificate, as reported by the mother. 
We undertook an initial bivariate analysis of all the candidate variables with the outcome of interest. For each set of variables (access to Western healthcare, education, economic conditions, family relations and engagement with the modern state), we then included in the multivariate analysis the variable with the strongest association with the outcome in bivariate analysis, in order to avoid including non-independent variables in the same multivariate model. From an initial multivariate model that included all these candidate variables from the bivariate analysis, we used backward deletion one variable at a time until only significant associations remained, using a conservative threshold $\left(\chi^{2}\right.$ Mantel-Haenszel $\left.\left(\chi^{2} M H\right)>6.65\right)$ for significance, to allow for testing multiple variables without prior specification in the study design.

Statistical analysis relied on CIETmap $2.0 \quad \beta \quad 9.5$, a Windows-like interface with the $\mathrm{R}$ programming language. $^{24}$ We expressed associations as adjusted ORs (ORa) and 99\% CIs using the method of Miettinen, adjusted for clustering with the method of Lamothe (CIca) to avoid overestimation of statistical confidence. ${ }^{25}$ Analysis of the non-linear gradient between use of traditional medicine and level of education used Mantel's extension of the Mantel-Haenszel procedure. ${ }^{26}$ Analysis excluded records with missing data.

\section{Ethics}

The Cross River State Research Ethics Committee approved the methodology and survey instruments in August 2009, with renewals for the 2011 and 2013 surveys. Local government and traditional authorities gave permission for fieldwork in each community. Before each interview, the interviewer obtained verbal informed consent, explained that responses were voluntary and could be stopped at any time, and explained the provisions of confidentiality and anonymity. The interviews with traditional medical practitioners followed ethical principles for medical research in indigenous communities. $^{27}$

\section{RESULTS}

\section{Traditional medical practitioners}

Interviews with traditional practitioners revealed different forms of traditional medicine, reflecting the diversity of Cross River State. Practitioners described themselves as birth attendants, native doctors, bone setters, religious leaders, medicine sellers and people with knowledge of traditional medicine. They described their interface with government health services as a limited number of specific moments: registration as a traditional medical practitioner; traditional birth attendants receiving Western training; and, in remote communities, government health promoters referring certain types of cases to traditional practitioners.

Traditional practitioners explained that their medical pharmacopoeia is plant based, with prayers and invocations to activate or to potentiate the effect. Plants from the bush or forests are considered more powerful than those that grow close to dwellings, and more appropriate for treatment of advanced or complicated conditions.

\section{The sample}

Of 90 clusters in the sample, 60 were rural and 30 urban. Interviewers covered 7685 households $(75.5 \%$ of the 10231 households in the enumeration areas), with an average of 85.4 households per cluster (SD 13.4); $58.6 \%(4503 / 7685)$ of households had fewer than five occupants. Some $9.9 \%$ of the households $(760 / 7685)$ were in hard-to-reach communities, most were maleheaded $(82.8 \%$ or $6361 / 7682)$, and $57.2 \%(4354 / 7613)$ of the households heads were engaged in low-paying occupations.

Among women who responded to the questionnaire, $90.3 \%(7306 / 8089)$ reported on the health of 11305 children in the past 2 years; $48.3 \%$ (3525/7306) answered for more than 1 child. Women respondents had a mean age of 26.9 years (n 7975, SD 7.7) and an average of three children (n 7321, SD 1.9). Nearly all the women $(7423 / 7938)$ had some formal education: $63.2 \%(5017 / 7938)$ had primary education and $7.8 \%$ $(618 / 7938)$ had a high school diploma. More than one half $(55.5 \%$ or $4423 / 7974)$ of the women reported a source of income of their own.

\section{Childbirth attended by traditional medical practitioners}

Some $71.8 \%$ (5735/7985) of women had been pregnant during the past 2 years (1.3\% missing data 104/8089), and $24.1 \%(1371 / 5686)$ reported that their last delivery was attended by a traditional medical practitioner. A further $33.4 \%(1900 / 5686)$ delivered at government facilities and $15.1 \%(858 / 5686)$ at private facilities; $21.7 \%$ (1232/5686) reported deliveries attended by other non-professional services (pharmacies, churches, a relative or neighbour), and 5.7\% (325/5686) reported having delivered their child at home unattended. There were no data on place of delivery for under 1\% (49/ 5686) of respondents.

Some $76.8 \%(4367 / 5686)$ of the women reported attending government antenatal care during their last pregnancy. In bivariate analysis, women who attended government antenatal care were significantly less likely to use a traditional practitioner for childbirth (ORa 0.31 $99 \%$ CIca 0.22 to 0.41 ). Table 1 shows the bivariate analysis of all variables examined for association with use of traditional practitioners for childbirth. Table 2 presents the final multivariate model with four variables showing independent statistically significant associations after adjusting for the other three.

\section{Children with diarrhoea seen by traditional medical practitioners}

Mothers or caregivers answered questions about treatment of the last episode of diarrhoea in 5416 children 
Table 1 Bivariate analysis of associations with having childbirth attended by a traditional practitioner, among women aged $15-49$ years who gave birth in the past 2 years

\begin{tabular}{|c|c|c|c|c|c|}
\hline Characteristic & Exposed & Non-exposed & OR & 99\% Clca* & $\begin{array}{l}\text { Missing } \\
\text { data }(\%)\end{array}$ \\
\hline \multicolumn{6}{|l|}{ Availability of Western healthcare } \\
\hline Antenatal care in a government facility* & $808 / 4349$ & $560 / 1300$ & 0.31 & 0.22 to 0.41 & 0.7 \\
\hline \multicolumn{6}{|l|}{ Education } \\
\hline Woman with postsecondary or higher education* & $31 / 451$ & 1330/5201 & 0.25 & 0.13 to 0.37 & 0.6 \\
\hline Woman with junior high education or higher & $729 / 3629$ & $632 / 2023$ & 0.57 & 0.43 to 0.72 & 0.6 \\
\hline Woman with any formal education & $1293 / 5349$ & $68 / 303$ & 1.21 & 0.71 to 1.71 & 0.6 \\
\hline Household head with postsecondary or higher & $91 / 832$ & $1249 / 4716$ & 0.36 & 0.24 to 0.48 & 2.4 \\
\hline Household head with junior high or higher & $730 / 3596$ & $610 / 1952$ & 0.58 & 0.44 to 0.72 & 2.4 \\
\hline Household head with any formal education & $1237 / 5143$ & $103 / 405$ & 0.99 & 0.65 to 1.33 & 2.4 \\
\hline \multicolumn{6}{|l|}{ Economic condition } \\
\hline Household of good construction* & $796 / 3729$ & $566 / 1922$ & 0.68 & 0.47 to 0.90 & 0.6 \\
\hline Self-rated economic condition above community average & $805 / 3673$ & $558 / 1979$ & 0.73 & 0.58 to 0.89 & 0.6 \\
\hline Enough food last week & $1081 / 4616$ & 290/1065 & 0.85 & 0.63 to 1.06 & 0.1 \\
\hline Household with safer water source & $538 / 2340$ & $824 / 3306$ & 0.97 & 0.60 to 1.35 & 0.7 \\
\hline Not living in a hard-to-reach community & $1203 / 5108$ & $168 / 578$ & 1.02 & 0.33 to 1.71 & 0.0 \\
\hline Household using fuel other than charcoal or wood & $365 / 1486$ & $994 / 4161$ & 1.10 & 0.73 to 1.48 & 0.7 \\
\hline Living in an urban community & $457 / 1916$ & $914 / 3770$ & 1.17 & 0.53 to 1.81 & 0.0 \\
\hline \multicolumn{6}{|l|}{ Family relations } \\
\hline Not verbally abused by partner in past 12 months* & $344 / 1728$ & $856 / 3267$ & 0.72 & 0.57 to 0.86 & 12.2 \\
\hline Does not report that neighbours were verbally abused & $143 / 731$ & $1064 / 4285$ & 0.76 & 0.57 to 0.95 & 11.8 \\
\hline Not beaten by partner during past pregnancy & $855 / 3760$ & $347 / 1236$ & 0.77 & 0.62 to 0.92 & 12.1 \\
\hline Not beaten by partner in past 12 months & $616 / 2807$ & $588 / 2192$ & 0.78 & 0.63 to 0.93 & 12.1 \\
\hline $\begin{array}{l}\text { Talked frequently with partner about pregnancy and } \\
\text { delivery }\end{array}$ & $847 / 3738$ & $515 / 1904$ & 0.80 & 0.65 to 0.96 & 0.8 \\
\hline \multicolumn{6}{|l|}{ Engagement with the modern state } \\
\hline Mother of a child with birth certificate & $465 / 2558$ & $872 / 2967$ & 0.55 & 0.42 to 0.69 & 2.8 \\
\hline From a community with electricity service & $889 / 3920$ & $401 / 1514$ & 1.06 & 0.38 to 1.74 & 4.4 \\
\hline
\end{tabular}

*Variables included in the initial multivariate model.

Clca, Cls using the method of Miettinen, adjusted for clustering with the method of Lamothe.

who had consulted for their last episode of diarrhoea. In response to the question about where the child was taken first, the local pharmacy was the most common reported source of treatment: $41.8 \%(2266 / 5416)$ of cases. Traditional medicine was reported to be the first source of treatment in $1.6 \%(85 / 5416)$ of cases of diarrhoea. Among the 33.6\% (1871/5416) of mothers who reported another source of treatment for the same episode, 29.3\% (549/1871) said that they used traditional medicine. Combining first and second sources of treatment, $11.3 \%(615 / 5416)$ of mothers reported that they used traditional medicine for childhood diarrhoea.
Children of mothers whose last delivery was attended by a traditional medical practitioner were significantly more likely to be taken to a traditional medicine practitioner for common childhood illnesses (ORa 1.86, 99\% CIca 1.24 to $2.48 \chi^{2} \mathrm{MH} 28.9$ ). Bivariate analysis (table 3) showed that children who had received BCG vaccination (as an indicator of access to Western medicine) were significantly less likely to be treated by a traditional medicine practitioner for diarrhoea (ORa 0.37 99\% CIca 0.26 to 0.49 ).

Variables in the initial multivariate analysis model included: children who had received BCG vaccine,

Table 2 Final multivariate analysis of variables associated with childbirth attended by a traditional practitioner

\begin{tabular}{lllll}
\hline $\mathbf{n}=\mathbf{4 8 2 0}$ & Crude OR & Adjusted OR & $\mathbf{9 9 \%}$ Clca & cl adj $\boldsymbol{\chi}^{2} \mathbf{M H}$ \\
\hline Attended government antenatal care & 0.28 & 0.33 & 0.21 to 0.50 & 45.75 \\
Postsecondary or higher education & 0.23 & 0.34 & 0.21 to 0.56 & 31.12 \\
Mother of a child with birth certificate & 0.53 & 0.69 & 0.53 to 0.90 & 13.36 \\
Not verbally abused by partner in past 12 months & 0.72 & 0.80 & 0.65 to 0.99 & 7.58 \\
\hline
\end{tabular}

The variable for 'Household of good construction' was also included in the initial multivariate model but it did not remain statistically significant.

Clca, Cls using the method of Miettinen, adjusted for clustering with the method of Lamothe; cl adj $\chi^{2} \mathrm{MH}, \mathrm{Cluster}$-adjusted $\chi^{2}$ of Mantel-Haenszel. 
Table 3 Bivariate analysis of associations with use of traditional medicine for childhood diarrhoea

\begin{tabular}{|c|c|c|c|c|c|}
\hline Characteristic & Exposed & Non-exposed & $\begin{array}{l}\text { Adjusted } \\
\text { OR }\end{array}$ & $99 \%$ Clca & $\begin{array}{l}\text { Missing } \\
\text { data (\%) }\end{array}$ \\
\hline \multicolumn{6}{|l|}{ Availability of Western healthcare } \\
\hline Children received BCG vaccine* & $532 / 5091$ & $74 / 299$ & 0.37 & 0.26 to 0.49 & 0.7 \\
\hline \multicolumn{6}{|l|}{ Education } \\
\hline $\begin{array}{l}\text { Household head has postsecondary or higher } \\
\text { education* }\end{array}$ & $34 / 765$ & $567 / 4550$ & 0.37 & 0.20 to 0.54 & 2 \\
\hline Household head has junior high education or higher & $281 / 3217$ & $320 / 2098$ & 0.55 & 0.42 to 0.68 & 2 \\
\hline Household head has any formal education & $528 / 4811$ & $73 / 504$ & 0.77 & 0.52 to 1.03 & 2 \\
\hline Mother/caregiver has postsecondary or higher education & $13 / 317$ & $571 / 4788$ & 0.44 & 0.14 to 0.73 & 5.9 \\
\hline Mother/caregiver has junior high education or higher & $267 / 3085$ & $317 / 2020$ & 0.53 & 0.37 to 0.70 & 5.9 \\
\hline Mother/caregiver has any formal education & $529 / 4777$ & $55 / 328$ & 0.69 & 0.38 to 0.99 & 5.9 \\
\hline Father has postsecondary or higher education & $39 / 831$ & $525 / 4334$ & 0.40 & 0.22 to 0.59 & 4.8 \\
\hline Father has junior high education or higher & $320 / 3622$ & $244 / 1543$ & 0.53 & 0.40 to 0.66 & 4.8 \\
\hline Father has any formal education & $528 / 4893$ & $36 / 272$ & 0.88 & 0.50 to 1.25 & 4.8 \\
\hline \multicolumn{6}{|l|}{ Economic conditions } \\
\hline $\begin{array}{l}\text { From a household using fuel other than charcoal or } \\
\text { wood }^{*}\end{array}$ & $71 / 1048$ & $539 / 4345$ & 0.56 & 0.34 to 0.78 & 0.6 \\
\hline From a household with a safer water source & $186 / 2095$ & $428 / 3307$ & 0.69 & 0.47 to 0.91 & 0.4 \\
\hline From a household with good quality construction & $332 / 3351$ & 282/2051 & 0.72 & 0.51 to 0.93 & 0.4 \\
\hline Not living in a hard-to-reach community & $523 / 4832$ & $92 / 593$ & 0.79 & 0.35 to 1.23 & 0.0 \\
\hline Living in an urban community & $139 / 1529$ & $476 / 3896$ & 0.81 & 0.43 to 1.19 & 0.0 \\
\hline With enough food last week & $452 / 4091$ & $133 / 1031$ & 0.88 & 0.62 to 1.14 & 5.6 \\
\hline $\begin{array}{l}\text { From a household considering their financial situation as } \\
\text { above average for the community }\end{array}$ & $370 / 3394$ & $242 / 2004$ & 0.92 & 0.68 to 1.17 & 0.5 \\
\hline \multicolumn{6}{|l|}{ Family relations } \\
\hline Mother not beaten by partner during past pregnancy* & $309 / 3073$ & $158 / 1070$ & 0.67 & 0.48 to 0.87 & 23.7 \\
\hline Mother not beaten by partner in past 12 months & $214 / 2225$ & 253/1922 & 0.73 & 0.53 to 0.93 & 23.6 \\
\hline Mother not verbally abused by partner in past 12 months & $115 / 1232$ & $351 / 2911$ & 0.78 & 0.56 to 1.00 & 23.6 \\
\hline $\begin{array}{l}\text { Mother does not report that neighbours were verbally } \\
\text { abused }\end{array}$ & $43 / 497$ & $426 / 3659$ & 0.82 & 0.43 to 1.20 & 23.4 \\
\hline $\begin{array}{l}\text { Mother talked frequently with partner about pregnancy } \\
\text { and delivery }\end{array}$ & $342 / 3053$ & $174 / 1592$ & 1.06 & 0.79 to 1.33 & 14.4 \\
\hline \multicolumn{6}{|l|}{ Engagement with the modern state } \\
\hline Child has a birth certificate* & $189 / 2539$ & $418 / 2799$ & 0.48 & 0.34 to 0.61 & 1.6 \\
\hline From a community with electricity service & $328 / 3700$ & $246 / 1524$ & 0.55 & 0.33 to 0.78 & 3.7 \\
\hline
\end{tabular}

household head with postsecondary studies or higher, households using fuel for cooking other than charcoal or wood, children of a mother not beaten by her partner during her last pregnancy, and children with a birth certificate.

Table 4 shows the final model of the multivariate analysis of variables associated with children with diarrhoea being taken to a traditional medicine practitioner. Table 5 shows a clear, if non-linear, trend between higher educational levels among women and a lower reliance on traditional medicine for childbirth and diarrhoea.

\section{DISCUSSION}

One in every four women $(24.1 \%, 1371 / 5686)$ in Cross River State had her last delivery attended by a traditional practitioner and 1 in every 10 children (11.3\%, 615/ 5425) was taken to a traditional practitioner to treat their last case of diarrhoea. Use of traditional medicine was convincingly associated with non-use of Western medical services, lower levels of education, increased risk of family violence, and lack of engagement with the modern state as reflected in children not having birth certificates. Our findings indicate that any enquiry into the effectiveness of traditional medicine should take careful account of these covariates which could be determinants of health in their own right.

This is one of the few population-based representative studies of the use of traditional medicine and associations with this behaviour. Our data probably underestimate the actual use of traditional medicine as people may hide their preferences for traditional medicine in the face of stigma. ${ }^{28}$ Mothers in our study rarely spontaneously mentioned traditional medicine when asked where they took a child with diarrhoea, but more often mentioned it when encouraged to say where else they had taken the child. This may reflect stigma associated with the use of traditional medicine. From a cross-sectional study, one 
Table 4 Final multivariate analysis of variables associated with children being taken to a traditional medical practitioner for treatment of diarrhoea

\begin{tabular}{lllll}
\hline $\mathbf{N}=\mathbf{5 1 8 0}$ & Crude OR & Adjusted OR & $\mathbf{9 9 \%}$ Clca & cl adj $\chi^{2} \mathbf{M H}$ \\
\hline Household head has postsecondary higher education & 0.32 & 0.39 & 0.26 to 0.59 & 34.6 \\
Children with BCG vaccine & 0.36 & 0.46 & 0.29 to 0.72 & 20.1 \\
Child with a birth certificate & 0.47 & 0.56 & 0.42 to 0.75 & 27.3 \\
From a household using fuel other than charcoal or wood & 0.51 & 0.63 & 0.43 to 0.92 & 10.01 \\
\hline
\end{tabular}

The variable 'Mother not beaten by partner during past pregnancy' was also included in the initial multivariate model but it did not remain significant.

Clca, Cls using the method of Miettinen, adjusted for clustering with the method of Lamothe; cl adj $\chi^{2} \mathrm{MH}$, Cluster-adjusted $\chi^{2}$

Mantel-Haenszel.

cannot draw firm conclusions about causal relations. For example, we cannot say that increased education caused decreasing use of traditional medicine. However, the association between lower education and greater use of traditional medicine would make it difficult to measure the full impact of traditional medicine on health, because education itself is such a strong determinant of health status and health reporting.

Pharmacies were the first resource for treating childhood diarrhoea in Cross River State (41.8\%). The 2010 malaria indicator survey found a similar result for childhood fever, ${ }^{29}$ a pattern of self-medication that is well recognised in Nigeria. ${ }^{18} 30$ Our finding that women rarely mentioned visiting traditional practitioners for treatment of children with diarrhoea when first asked, but revealed these visits when asked about any other sources of treatment, is in line with findings from two studies in Ghana. ${ }^{31}{ }^{32}$ This suggests that it is important to allow survey respondents to mention more than one source of care if they are to disclose use of traditional medicine. In this study, we did not establish whether choice of Western medicine preceded or followed traditional medicine, although this could be the focus of further research.

Although other authors have reported an association between urban residence and using formal health facilities for antenatal care and delivery, ${ }^{33}$ we did not find a significant association between use of traditional medical practitioners for childbirth or treatment of childhood diarrhoea and residence in rural or hard-to-reach communities. This suggests that traditional medicine is commonly used in all types of community in Cross River State. A study in Aba City, Nigeria, interviewed 19 urban women seeking treatment from rural traditional medicine practitioners of different ethnicity and found their reasons for going to these traditional practitioners included failure of urban health services to provide a cure, beliefs about the cause of their condition, the nature of their condition and a wish to maintain secrecy. ${ }^{35}$

Although affordability has been recognised as an important factor associated with traditional medicine, in Nigeria treatment choice involves cultural factors as well as cost of services. ${ }^{36}$ In our multivariate analysis of use of traditional medicine in childbirth, socioeconomic variables did not remain as significant associations in the final model. Onwujekwe $e t a l^{37}$ found no significant difference between low and high socioeconomic status and the quality of the providers used for malaria treatment in southeast Nigeria.

We found a significant association between experience of family violence and childbirth attended by traditional medicine practitioners. We cannot conclude this relation is causal or in which direction it might be causal. Other authors have reported a strong influence of family and

Table 5 Trend analysis of use of traditional medicine and education level of the women

\begin{tabular}{|c|c|c|c|c|c|}
\hline \multicolumn{6}{|c|}{ Education level and childbirth attended by a traditional medical practitioner } \\
\hline Woman & No education & Elementary & Junior High & Senior High & Higher education \\
\hline $\begin{array}{l}\text { Traditional medicine during childbirth } \\
\text { Other source of care for childbirth } \\
\text { Total } \\
\text { OR } \\
\text { Mantel-Haenszel } \chi^{2} \text { for trend }=135.21 \mathrm{~d}\end{array}$ & $\begin{array}{l}67 \\
233 \\
300\end{array}$ & $\begin{array}{l}564 \\
1156 \\
1720 \\
1.85\end{array}$ & $\begin{array}{l}259 \\
607 \\
866 \\
0.97\end{array}$ & $\begin{array}{l}439 \\
1873 \\
2312 \\
0.55\end{array}$ & $\begin{array}{l}31 \\
420 \\
451 \\
0.25\end{array}$ \\
\hline \multicolumn{6}{|c|}{$\begin{array}{l}\text { Mantel-Haenszel } \chi^{2} \text { for trend }=135.21 \mathrm{df} \\
\text { Education level and diarrhoea attended by a traditional medical practitioner }\end{array}$} \\
\hline Mother or caregiver & No education & Elementary & Junior high & Senior high & Higher education \\
\hline $\begin{array}{l}\text { Traditional medicine for diarrhoea } \\
\text { Other treatments for diarrhoea } \\
\text { Total } \\
\text { OR } \\
\text { Mantel-Haenszel } \chi^{2} \text { for trend=77.21df }\end{array}$ & $\begin{array}{l}55 \\
271 \\
326\end{array}$ & $\begin{array}{l}262 \\
1430 \\
1692 \\
1.01\end{array}$ & $\begin{array}{l}99 \\
706 \\
805 \\
0.81\end{array}$ & $\begin{array}{l}155 \\
1808 \\
1963 \\
0.53\end{array}$ & $\begin{array}{l}13 \\
304 \\
317 \\
0.44\end{array}$ \\
\hline
\end{tabular}


relatives in the decision about where to seek pregnancy and childbirth care. ${ }^{38}$ Traditional medicine is relatively low in cost compared with Western healthcare; costrelated decisions could be a plausible explanation for what might be an indirect association with family violence. Families where a woman is subjected to violence might also be unwilling to pay for her to have more expensive Western medical care in pregnancy and childbirth.

In our analysis, children with birth certificates-a marker of engagement with modern state institutionswere more likely to be taken to government health facilities for treatment of diarrhoea. In an analysis based on the same survey, children with birth certificates were also more likely to have educated parents, to have mothers who delivered in a government health facility and to live in less poor households. ${ }^{15}$

Our striking gradient between levels of education and reliance on traditional medicine for both childbirth and childhood diarrhoea agrees with the findings of other studies in Nigeria. ${ }^{34} 3839$ Western education is often accompanied by beliefs and values that neglect and sometimes condemn traditional practices as Western-trained educators strive to 'educate and convince women to dispel myths which limit their use of orthodox care'. ${ }^{40}$ The negative effects of forced Western education on the health of Indigenous people has been a matter of discussion in North America. ${ }^{42}$

Our findings are compatible with a 'transitional society where both traditional and modern medicine are employed and where the choice between them is determined by belief systems which are themselves in the process of change'. ${ }^{43}$ We believe that use or abandonment of traditional medicine is part of the transition from traditional to modern, a transition unevenly mediated through education, which influences health status in complex ways. ${ }^{45}$ Not least of these influences are the economic opportunities and incomes that come with modern education. It seems plausible that people using traditional medicine face harsher conditions of life (less education, less access to modern state machinery, less use of Western health services and low socioeconomic status) producing, interacting with and possibly multiplying health burdens. ${ }^{42}$ These variables should be included as possible covariates in analyses of the efficacy of traditional medicine.

Our study was a secondary analysis of data from a survey not designed to answer the question of who uses traditional medicine. Future studies specifically focusing on the use of traditional medicine should include intercultural dialogue with traditional practitioners as part of the design. ${ }^{46}{ }^{47}$ This dialogue could help to refine the research question and identify factors that influence the use of traditional medicine.

\section{CONCLUSIONS}

Availability of Western medicine was a factor in the abandonment of traditional medicine, but education, family relationships and linkages with government institutions also played important roles. The prominence of education suggests complex connections between the use of traditional medicine and cultural transition.

Given its continued importance in countries like Nigeria, formal studies to assess effectiveness of traditional medicine are much needed to optimise healthcare services and to improve health outcomes. Epidemiology applied to this traditional knowledge should be based on intercultural dialogue, better recognition and documentation of the social, economic and cultural factors in health outcomes, and should take into account the role of Western education in acculturation and the uneven loss of traditional medicine practices.

Acknowledgements Traditional doctors of Cross River took part in a dialogue with the researchers and offered ideas for analysis and interpretation of results. The CIET Trust team undertook the household survey and digitised the data. Dr Anne Cockcroft, Dr Khalid Omer, Noor Ansari and Obrian Nyamucherera contributed ideas on the subject of traditional medicine. Dr Anne Cockcroft critically reviewed and verified the English translation of the manuscript. Johanna Spans, Paloma Cruz, Carolina Amaya and Brenda Atkinson supported the analysis and write-up. The Centro de Estudios Medicos Interculturales (CEMI) contributed expertise on intercultural dialogue.

Contributors IS designed the study and supported fieldwork in Cross River; he also analysed the data and drafted the manuscript. GZ supervised the data analysis and contributed to the manuscript. NA designed the overall study in which this is embedded, and contributed to the data analysis and write-up. IS, GZ and NA had access to the data and all authors had final responsibility for the decision to submit for publication. All authors read and approved the final manuscript.

Funding This work was part of the Nigeria Evidence-Based Health System Initiative (NEHSI), funded by Foreign Affairs, Trade and Development, Canada (DFATD) and Canada's International Development Research Centre (grant number 104613-026) and implemented by the CIET Trust.

Competing interests NA and IS report grants from Foreign Affairs, Trade and Development, Canada and from Canada's International Development Research Centre during the conduct of the study.

Disclaimer The sponsors of the study had no role in study design, data collection, data analysis, data interpretation, or writing of the report.

Ethics approval The Cross River State Research Ethics Committee approved the methodology and survey instruments in August 2009, with renewals for the 2011 and 2013 surveys.

Provenance and peer review Not commissioned; externally peer reviewed.

Data sharing statement No additional data are available.

Open Access This is an Open Access article distributed in accordance with the Creative Commons Attribution Non Commercial (CC BY-NC 4.0) license, which permits others to distribute, remix, adapt, build upon this work noncommercially, and license their derivative works on different terms, provided the original work is properly cited and the use is non-commercial. See: http:// creativecommons.org/licenses/by-nc/4.0/

\section{REFERENCES}

1. World Health Organization. WHO Traditional Medicine Strategy 2014-2023. Geneva, Switzerland, 2013. http://apps.who.int/iris/ handle/10665/92455 (accessed 20 Feb 2016).

2. World Health Organization. WHO Traditional Medicine Strategy 2002-2005. Geneva, Switzerland, 2002. http://www.who.int/ medicines/publications/traditionalpolicy/en/ (accessed 20 Feb 2016).

3. World Health Organization. General guidelines for methodologies on research and evaluation of traditional medicine. Geneva, Switzerland, 2000. http://apps.who.int/medicinedocs/en/d/ Jwhozip42e/ (accessed 20 Feb 2016). 
4. Hersch-Martínez P. Epidemiología sociocultural: una perspectiva necesaria. Salud Publica Mex 2013;55:512-18. http://www. medigraphic.compdfs/salpubmex/sal-2013/sal135i.pdf (accessed 20 Feb 2016).

5. National Population Commission (NPC) [Nigeria] and ICF International. Nigeria Demographic and Health Survey 2013. Abuja, Nigeria, Rockville, MD, USA: NPC and ICF International, 2014. http://www.population.gov.ng/images/ndhs_data/ndhs_2013/2013_ ndhs_final_report.pdf (accessed 20 Feb 2016).

6. World Health Organization. World Health Statistics 2012. Geneva, Switzerland, 2012. http://apps.who.int/iris/bitstream/10665/44844/1/ 9789241564441_eng.pdf?ua=1 (accessed 20 Feb 2016).

7. The World Bank. World Development Indicators 2015. Washington DC, USA, 2015. https://openknowledge.worldbank.org/handle/ 10986/21634 (accessed 20 Feb 2016).

8. World Health Organization. Progress report on decade of traditional medicine in the African Region. Côte d'Ivoire, 2011. http://www.afro. who.int/en/downloads/doc download/6665-afrrc61pr2-progressreport-on-decade-of-traditional-medicine-in-the-african-region.html (accessed 20 Feb 2016)

9. Kasilo OMJ, Nikiema JB, Ota MMO, et al. Enhancing the role of traditional medicine in health systems: a strategy for the African Region. African Health Monitor 2013:18:40-3.

10. Offiong DA. Traditional healers in the Nigerian health care delivery system and the debate over integrating traditional and scientific medicine. Anthropol Q 1999;72:118-30.

11. Fakeye TO, Adisa R, Musa IE. Attitude and use of herbal medicines among pregnant women in Nigeria. BMC Complement Altern Med 2009;9:53.

12. Adejumo A, Faluyi M, Adejuwon A. Role of socio-psychological factors in perceived quality of care rendered by traditional medical practitioners in Ibadan, Nigeria. Glob J Health Sci 2013;5:186-96.

13. International Development Research Centre. Nigeria Evidencebased Health System Initiative. http://www.idrc.ca/en/aboutus/donor partnerships/pages/nehsi.aspx (accessed 20 Feb 2016).

14. Andersson N, Omer K, Caldwell D, et al. Male responsibility and maternal morbidity: a cross-sectional study in two Nigerian states. BMC Health Serv Res 2011;11(Suppl 2):S7.

15. Adi AE, Abdu T, Khan A, et al. Understanding whose births get registered: a cross sectional study in Bauchi and Cross River states, Nigeria. BMC Res Notes 2015;8:79.

16. Ansari $U$, Cobam B, Etim EM, et al. Insights into intimate partner violence in pregnancy: findings from a cross-sectional study in two states of Nigeria. Violence Against Women 2015;21:NP1.

17. Hamel $\mathrm{C}$, Enne $\mathrm{J}$, Omer $\mathrm{K}$, et al. Childhood malnutrition is associated with maternal care during pregnancy and childbirth: a cross-sectional study in Bauchi and Cross River State, Nigeria. J Public Health Res 2015;4:58-64.

18. Odu BP, Mitchell S, Isa $\mathrm{H}$, et al. Equity and seeking treatment for young children with fever in Nigeria: a cross-sectional study in Cross River and Bauchi States. Infect Dis Poverty 2015;4:1-9.

19. Cockcroft A, Usman MU, Nyamucherera OF, et al. Why children are not vaccinated against measles: a cross-sectional study in two Nigerian states. Arch Public Health 2014;72:48.

20. Eteng M, Mitchell S, Garba L, et al. Socio-economic determinants of ownership and use of treated bed nets in Nigeria: results from a cross-sectional study in Cross River and Bauchi States in 2011. Malar J 2014:13:316.

21. Omer K, Afi NJ, Baba MC, et al. Seeking evidence to support efforts to increase use of antenatal care: a cross-sectional study in two states of Nigeria. BMC Pregnancy Childbirth 2014:14:380.

22. Zuluaga G. Plantas medicinales y etnografía: Un enfoque ético para la Etnobiología. Bol Antropol Pontif Univ Javeriana 2000;6:21-32. http://media.wix.com/ugd/cb47c9 50ec344bc3144a9f85886 cce64c9425e.pdf (accessed 20 Feb 2016).

23. Babalola S, Lawan U. Factors predicting BCG immunization status in northern Nigeria: a behavioral-ecological perspective. J Child Health Care 2009;13:46-62.

24. Wikipedia. CIETmap. 2015. http://en.wikipedia.org/wiki/CIETmap (accessed 30 Nov 2015).
25. Andersson N, Lamothe G. Clustering and meso-level variables in cross-sectional surveys: an example of food aid during the Bosnian crisis. BMC Health Serv Res 2011;11(Suppl 2):S15.

26. Mantel N. Chi-square tests with one degree of freedom; extensions of the Mantel-Haenszel procedure. J Am Stat Assoc 1963;58:690-700.

27. Zuluaga $\mathrm{G}$. Una ética para la investigación médica con comunidades indígenas. In: Vélez A, Ruiz A, Torres M, eds. Retos y dilemas de los comités de ética en investigación. Bogotá: Editorial Universidad del Rosario, 2013:259-81. http://media.wix.com/ugd/ cb47c9_d790340d497847e58f5505518c122b24.pdf (accessed 20 Feb 2016).

28. Banda Y, Chapman V, Goldenberg RL, et al. Use of traditional medicine among pregnant women in Lusaka, Zambia. J Altern Complement Med 2007;13:123-7.

29. National Population Commission (NPC) [Nigeria], National Malaria Control Programme (NMCP) [Nigeria], ICF International. Nigeria malaria indicator survey 2010. Abuja, Nigeria, 2012. http:// dhsprogram.com/publications/publication-MIS8-MIS-Final-Reports. cfm (accessed 20 Feb 2016).

30. Goodman C, Brieger W, Unwin A, et al. Medicine sellers and malaria treatment in Sub-Saharan Africa: what do they do and how can their practice be improved? Trop Med Int Health 2007;77:203-18.

31. Tabi MM, Powell M, Hodnicki D. Use of traditional healers and modern medicine in Ghana. Int Nurs Rev 2006;53:52-8.

32. Sato A. Revealing the popularity of traditional medicine in light of multiple recourses and outcome measurements from a user's perspective in Ghana. Health Policy Plan 2012;27:625-37.

33. Gayawan E. Spatial analysis of choice of place of delivery in Nigeria Sex Reprod Healthc 2014;5:59-67.

34. Rai RK, Singh PK, Singh L, et al. Individual characteristics and use of maternal and child health services by adolescent mothers in Niger. Matern Child Health J 2014;18:592-603.

35. Izugbara CO, Etukudoh IW, Brown AS. Transethnic itineraries for ethnomedical therapies in Nigeria: Igbo women seeking Ibibio cures. Health Place 2005;11:1-14.

36. Chukwuneke FN, Ezeonu CT, Onyire BN, et al. Culture and biomedical care in Africa: the influence of culture on biomedical care in a traditional African society, Nigeria, West Africa. Niger J Med 2012;21:331-3. http://www.ncbi.nlm.nih.gov/pubmed/23304931

37. Onwujekwe O, Hanson K, Uzochukwu B. Do poor people use poor quality providers? Evidence from the treatment of presumptive malaria in Nigeria. Trop Med Int Health 2011;16:1087-98.

38. Babalola S, Fatusi A. Determinants of use of maternal health services in Nigeria-looking beyond individual and household factors. BMC Pregnancy Childbirth 2009;9:43.

39. Amaghionyeodiwe L. Determinants of the choice of health care provider in Nigeria. Health Care Manag Sci 2008; 11:215-27.

40. Abdullahi AA. Trends and challenges of traditional medicine in Africa. Afr J Tradit Complement Altern Med 2011;8:115-23.

41. Okafor IP, Sekoni AO, Ezeiru SS, et al. Orthodox versus unorthodox care: a qualitative study on where rural women seek healthcare during pregnancy and childbirth in Southwest, Nigeria. Malawi Med $J$ 2014;26:45-9.

42. King M, Smith A, Gracey M. Indigenous health part 2: the underlying causes of the health gap. Lancet 2009;374:76-85.

43. Omorodion FI. The socio-cultural context of health behaviour among Esan communities, Edo State, Nigeria. Health Transit Rev 1993;3:125-36.

44. Feyisetan BJ, Asa S, Ebigbola JA. Mothers' management of childhood diseases in Yorubaland: the influence of cultural beliefs. Health Transit Rev 1997;7:221-34.

45. Chalmers B. African birth: childbirth in cultural transition. River Club, South Africa: Berev Publications, 1990.

46. Cameron M, Andersson N, McDowell I, et al. Culturally safe epidemiology: oxymoron or scientific imperative. Pimatisiwin 2010;8:89-116.

47. Pérez Ruíz ML, Argueta AV. Saberes indígenas y dialogo intercultural. Cultura Representaciones Sociales 2011;5:31-56. 